\title{
Effective classroom management skills in physical education at institute of teacher education
}

\author{
Mohd Taib Harun, Maslawati Mohamad, Muhammad Akbar Zahidi* \\ Faculty of Education, The National University of Malaysia, Selangor, Malaysia \\ Email address: \\ akbar_zahidi@yahoo.co.uk (M. A. Zahidi) \\ To cite this article: \\ Mohd Taib Harun, Maslawati Mohamad, Muhammad Akbar Zahidi. Effective Classroom Management Skills in Physical Education at \\ Institute of Teacher Education. Education Journal. Vol. 4, No. 2, 2015, pp. 60-63. doi: 10.11648/j.edu.20150402.12
}

\begin{abstract}
This study was about effective classroom management skills in physical education at institute of teacher education (ITE). The purpose of this study was to review effective classroom management skills in physical education for student participation at ITE. Besides, this study is implemented to identify how to deal with classroom management strategies with the focus on communication, behavior challenges, and discipline at ITE. It is important to identify how to keep our young students involved in physical education at ITE. It is not only important for their future but for the instructor to have control of such a large class. The research design was quantitative using a set of questionnaire. Then, it was analyzed by using SPSS 24.0. Next, the participants in this study were 112 physical education lecturers from 17 ITEs. All subjects were chosen according to their field of expertise and grade level. Participants agreed to be observed teaching and to also fill out a survey. Based on the findings, most of the lecturers responded that they strongly agree with the positive classroom management techniques and strongly disagree with the negative classroom management techniques at ITE. In conclusion, the study results showed that lecturers who utilized positive classroom management techniques were more likely to solicit cooperation from their students and felt less job stress.
\end{abstract}

Keywords: Classroom Management Skills, Physical Education, Institute of Teacher Education (ITE)

\section{Introduction}

Physical educators are concerned with how to manage their classrooms effectively to be able to have increased student participation at Institute of Teacher Education (ITE) [1]. The number of students in physical education was much higher than in a general educational class. Therefore, the demand for effective classroom management was much greater. Within classroom management there were many areas that were important to focus on such as communication, behavior challenges, routine and disciple. All of these skills must have some variable within the management of the physical education class, without any one of these skills the instructor could loose control of such a large number of students. It was imperative to be able to effectively manage a class this size [2]. Participation in physical education was a key for students' growth and development [3]. Physical Education offered a broad range of benefits for students, including character building the prevention of obesity, and self-confidence [4].

\subsection{Purpose of the Study}

The purpose of this study was to review effective classroom management skills in physical education for student participation at ITE. Besides, this study was implemented to identify how to deal with classroom management strategies with the focus on communication, behavior challenges, and disciple at ITE. It was important to identify how to keep our young students involved in physical education at ITE. It was not only important for their future but for the instructor to have control of such a large class.

\subsection{Research Questions}

There were some effective classroom management skills in physical education for student participation. The research questions in this study were:

1. How effective classroom management skills in physical education can improve student participation at ITE?

2. How to deal with classroom management strategies with the focus on communication, behavior challenges, and discipline at ITE? 
3. How to keep our young students involved in physical education at ITE?

\subsection{Significant of the Study}

The skills taught in physical education improve students' performance, sharpened their knowledge of strategy and tactics, and helped them to transfer knowledge from one context to another, including sport and recreational and outdoor activities. The concept of challenge by choice enabled appropriate learning at a level that builds confidence. This study had been more on classroom management skills and encouraged students to transfer knowledge to other learning areas.

\section{Review of Literature}

Physical education taught students to think critically about movement and movement contexts such as considering an issue from different points of view, identifying what was influencing the issue, and explaining how the influences were affecting the issue [1]. Learning to think critically encouraged students to participate in social action for a fairer, more equitable, and just society by reducing barriers to participation [2]. In this article, the authors, who were physical education teacher educators themselves, discussed the five management practices, which they have found to be the most essential techniques for physical education teachers to maintain a well-managed, productive learning environment. According to Owens (2006), Physical education teaches students to critically inquire into the social and cultural significance of movement, so that they can better understand what influences people to engage and participate in physical activity. The articles in this review suggest that physical activity can have an impact on cognitive skills and attitudes and academic behavior, all of which are important components of improved academic performance. These include enhanced concentration and attention as well as improved classroom behavior [3]

Besides, Zahidi and Akbar (2013) used their knowledge of student and teacher behavior to explain why teacher radar was important to the educational benefit of students. Even though there was no indication within this article or its source that data collection occurred, the author used constant comparison throughout. The article charts "Student Signals and Meanings" without indicating how or where the signals and meanings were developed [4]. The results of this article indicated that teachers need to have internal radar that focused on the mentality of each student to be able to create an environment to help the student who wanted to participate. Teachers should have a positive, pro-active approach to each student and class, utilizing good classroom management skills which the students were well aware of prior to any expectations [5].

Clark (2007) clearly stated that most students would participate and did well within the physical education classroom if the teacher was verbally aggressive. The students indicated that they did not learn the material, but would participate to avoid the repercussions of the teacher [1]. The participants were a random sample of 265 students (131 boys and 134 girls) ages 13-17 years from secondary schools in Greece. Based on the study, the more verbally aggressive a teacher was with the students the less the students value the lessons learned. The author warned that this study was conducted using student voices only. To obtain a clearer point of view regarding verbal aggressiveness within the physical education classroom, one should include questionnaires for the teachers [6].

The results stated that the participants viewed physical fitness testing, wellness assignments, instructional techniques, and meeting people positively. There were $63 \%$ of the positive responses were related to the curriculum. Students viewed the assignments administered in class as beneficial because it related closely to their homework assignments and shed light on their own personal fitness and wellness. Class activities were also viewed positively by students. Students felt the activities gave them information unique to their body type and allowed them to evaluate their individual fitness level.

According to Zahidi and Akbar (2013), negative perceptions were included class meeting times, classroom management and lack of team cohesion. Students identified the early class time of 8:00a.m. or 9:00a.m. negatively because they worried about being late to their next class. Some students reported a lack of variety of in class activities lead to boredom. Some participants felt that the exercise class was not challenging enough. These students would have liked the teacher to modify their workouts to meet their individual needs. Students stated that attendance taking could have been modified. Tardiness needed to be addressed and teacher talk during play time could have been minimized. A few students felt that they were not accepted by their team but for the most part students viewed the team dynamics positively.

Next, Zahidi and Akbar (2013) stated that to present a successful lesson you must set time aside for planning and organizing the flow of the lesson before the school year begins. This was crucial for both the teacher and the students. When a teacher developed a lesson well in advance they became familiar and comfortable with the content, made it easier to deliver. Becoming familiar with the school, community and classroom were essential to having success with classroom management. According to the article the classroom space can have a significant effect on classroom management [4]. For example, facilities for dance vary from a specific studio space, to multi-use auditoriums, to trailers. The nature and size of the space will affect lesson planning and classroom management [5].

Another essential component to having successful classroom management was how the material was introduced [3]. Class procedures were addressed during the introduction as well as key components of the physical education lesson. The introduction stated what the students will learn that day and it also reviews what was taught in the previous lesson. It was important for the teacher to notice students that were off 
task and made changes that address the behavior before it was intensified.

Transition times can be the most difficult time during a lesson [4]. Intervals between tasks can be problematic if the teacher was not organized. The article stated that reviewing rules, transition procedures and policies with the students on the first day of class can help smooth out transition difficulties. Addressing transition issues immediately will eliminate future behavior issues. The teacher needed to be consistent with their transition expectations, which will help with classroom management.

The results of this study were that physical education teachers will benefit from good planning, well designed instruction, focusing on smooth transitioning from one task to the next, organized performance times and being prepared for unexpected events. When a teacher focused on these areas they will have a more successful class with less classroom management challenges [4]

\section{Methodology}

\subsection{Research Design}

Our group decided to research how effective classroom management of physical education teachers enhanced students' participation at ITE. The research design was using a set of questionnaire. Then, it was analyzed by using SPSS 24.0 as shown in Table 1.

\subsection{Sample}

Participants in this study were 112 physical education lecturers from 17 ITEs. All subjects were chosen according to their field of expertise and grade level. Participants agreed to

be observed in teaching and fill out a survey.

All of our group members were interested in the topic of classroom management within a physical education class. This research looked at a survey and observations. Researchers selected the participants by choosing lecturers who were in the field of physical education and based on the grade level they taught. Researchers also created a questionnaire for the participants to fill out. One advantage of the survey was short and easy to administer. Each question had four answer options and there were easy for the participants to read the question and circle an answer. One disadvantage of the survey was that a small sample group. More time would have allowed researchers to administer more surveys and record more teacher observations. A larger sample group may have been more beneficial to this research.

\subsection{Instrumentation/Data Collection}

An advantage of using a rating scale for the answers was the ease of data collection analysis and identifying trends in successful classroom management techniques at ITE. A disadvantage of using a survey was the lack of personal details that an interview could permit.

\subsection{Data Treatment Procedures}

The completed surveys were analyzed by researchers using SPSS 24.0 quantitively. Six of the ten questions were related to positive classroom management techniques and four of the ten questions related to negative classroom management technique. The survey answers were added up in each category from strongly agree to strongly disagree.

\section{Findings}

Table 1. Statistic of Positive and Negative Classroom Management Techniques

\begin{tabular}{|c|c|c|c|c|}
\hline \multirow[b]{2}{*}{ Item } & \multicolumn{4}{|l|}{ Response } \\
\hline & Strongly Agree & Agree & Disagree & Strongly Disagree \\
\hline & 1 & 2 & 3 & 4 \\
\hline & $\mathbf{N}(\%)$ & $\mathbf{N}(\%)$ & $\mathbf{N}(\%)$ & $\mathbf{N}(\%)$ \\
\hline On average I have a large number of students actively participating during class. & $64(57)$ & $13(12)$ & $20(18)$ & $15(13)$ \\
\hline I am always in control of my students during class. & $45(40)$ & $32(28)$ & $15(13)$ & $20(18)$ \\
\hline I expect all of my students to participate in all activities. & $75(67)$ & $25(22)$ & $6(5)$ & $6(5)$ \\
\hline I reward my students for their participation. & $43(38)$ & $57(51)$ & $6(5)$ & $6(5)$ \\
\hline I model and set appropriate examples for my students. & $32(29)$ & $33(29)$ & $30(27)$ & $17(15)$ \\
\hline I reward good behavior in my class. & $39(35)$ & $43(38)$ & $15(13)$ & $15(13)$ \\
\hline Total Positive Classroom Management Scores & $50(45)$ & $34(30)$ & $15(13)$ & $13(12)$ \\
\hline I often feel frustrated at the end of my work day. & $10(9)$ & $11(10)$ & $67(60)$ & $24(21)$ \\
\hline I use a punitive system in my classroom management. & $2(2)$ & $3(3)$ & $32(29)$ & $75(66)$ \\
\hline I often need to raise my voice in order to get my students to participate. & $13(12)$ & $13(12)$ & $18(43)$ & $68(61)$ \\
\hline I ignore bad behavior in my class. & $12(11)$ & $7(6)$ & $54(48)$ & $39(35)$ \\
\hline Total Negative Classroom Management Scores & $9(8)$ & $9(8)$ & $51(45)$ & $52(46)$ \\
\hline
\end{tabular}

\subsection{Presentation of Findings}

Most of the lecturers responded that they strongly agree with the positive classroom management techniques and strongly disagree with the negative classroom management techniques at ITE. The study reported that lecturers who utilized positive classroom management techniques were 
more likely to solicit cooperation from their students and felt less job stress.

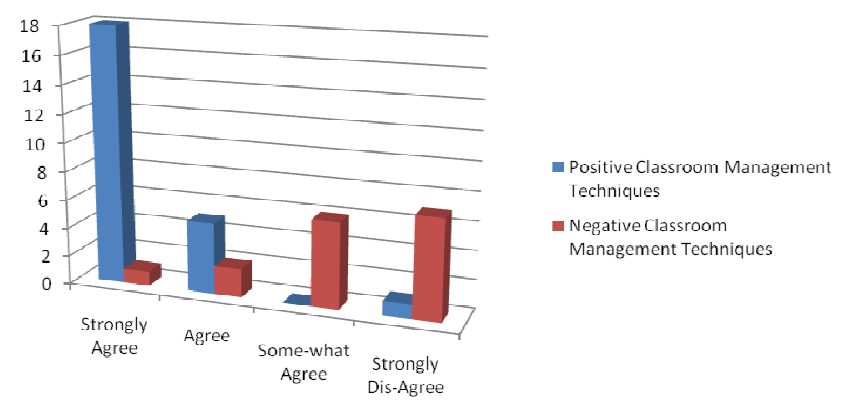

Figure 1. Graph of Positive and Negative Classroom Management Techniques

\subsection{Limitations of the Study}

Limitations of this study were ITE students. It excluded elementary and secondary students. Other limitations included the scope of scholarly journals. Only four scholarly journals and four surveys's were selected and included for this study. Time was also an issue when it came to developing a detailed survey. With more time our questions could have been more specific. Having a larger sample group would have also been beneficial to our study. A larger sample group would also have allowed researchers to include more observations which may have improved the study results.

\subsection{Conclusion}

This study focused on classroom management in physical education for ITE students' participation. Based on the findings, research level setting was chosen ITE because physical education was a critical school curriculum and also physical education was required for all students in middle school and two years minimal in high school. Physical education at the ITE level was also prepared students to meet the physical demands of every day life through a wide range of activities. The transition from childhood to young adulthood became complex at the ITE level. Students were self-directed, independent and eagerly seeking new challenges. The findings were not conclusive and would need further research.

\section{Recommendations for Further Research}

To build on this research further, it would be necessary to examine more articles. Besides, more data collection is also essential to further this study.

\section{References}

[1] Bekiari, A., Kokaridas, D., \& Sakellariou, K. (2006). Associations of students' self-reports of their teachers' verbal aggression, intrinsic motivation, and perceptions of reasons for discipline in greek physical education classes. Psychological Reports, 98(2), 451-461. Retrieved Mac 2, 2014,

[2] Clark, D. (2007). Classroom management challenges in the physical education class. European Physical Education Review, 3(5) 19-24.

[3] Hastie, P., \& Siedentop, D. (1999). An ecological perspective on physical education. European Physical Education Review, 5(1), 9. Retrieved July 4, 2014, from Academic Search Premier database.

[4] Jenkins, J., Jenkins, P., Collums, A., Werhonig, G. (2006). Student perceptions of a conceptual physical education activity course. Physical Educator, 63(4), 210-221.

[5] Owens, L. (2006). Teacher radar the view from the front of the class. Journal of Physical Education, Recreation \& Dance, 77(4), 29-33. Retrieved March 2, 2014, from Academic Search Premier database.

[6] Zahidi, M. A. \& Akbar, R. N. A. M. (2013). Management of disruptive behavior in physical education. Physical Educator, 47(1), 16-27. 